\title{
MONITORAMENTO DOS PROCESSOS HIDROEROSIVOS SUPERFICIAIS E ANÁLISES FÍSICO-QUÍMICAS DO TOPO DO SOLO EM CORTE DE ENCOSTA
}

\author{
Yolanda Tavares Molinaro ${ }^{(a)}$, Diego Janoti Suarez ${ }^{(b)}$, Leonardo dos Santos Pereira ${ }^{(c)}$, \\ Antonio José Teixeira Guerra ${ }^{(d)}$ \\ (a) Departamento de Geografia/ IGEO, Universidade Federal do Rio de Janeiro, E-mail: \\ yolanda_molinaro@hotmail.com \\ (b) Departamento de Geologia/ IGEO, Universidade Federal do Rio de Janeiro, E-mail: diarjel@ hotmail.com \\ (c) Departamento de Geografia/ IGEO, Universidade Federal do Rio de Janeiro, E-mail: leospgeo@ gmail.com \\ (d) Departamento de Geografia/ IGEO, Universidade Federal do Rio de Janeiro, E-mail: \\ antoniotguerra@gmail.com
}

\section{EIXO: SOLOS E PAISAGENS}

\begin{abstract}
Resumo
O presente estudo aborda a relação entre os totais pluviométricos observados no ano de 2016 e o processo de escoamento superficial, por meio do monitoramento de uma estação experimental. Isso se faz importante, pois a área de estudo está inserida em corte de encosta, promovendo alteração e desequilíbrio do comportamento hídrico e desencadeando processos erosivos, e danos ao meio ambiente. A área de estudo está inserida na sub-bacia hidrográfica do rio Maranduba, em Ubatuba/ São Paulo, onde se tem observado o crescente processo de urbanização e ocupação de encostas. A pesquisa teve como objetivo quantificar os totais de perda de solo e água superficialmente e relacionar essas respectivas perdas com a ação da chuva na área de estudo, além de demonstrar através de análises físico-químicas o processo de degradação da mesma.
\end{abstract}

Palavras-chave: Escoamento superficial. Erosão. degradação dos solos.

\section{Introdução}

A retirada da cobertura vegetal dos solos para a agricultura, construção civil, etc., influencia diretamente a perda de solo, pois dificulta a infiltração da água no mesmo, aumentando o escoamento superficial e dando origem a incisões e caminhos preferenciais para a água (FANTIN, 2012). Sendo assim, modificações feitas no relevo através de intervenção antrópica, como é o caso da presente área de estudo que sofreu corte de encosta, ocasionam alterações nas dinâmicas hidrológicas do mesmo, relacionadas aos fluxos superficiais e subsuperficiais de água no solo, aumentando o escoamento superficial e consequentemente a erosão.

Nesse sentido, a pesquisa visou desenvolver uma análise na superfície do solo que sofreu corte de encosta, para compreender e quantificar o processo de escoamento superficial da água no solo, assim 


\section{OS DESAFIOS DA GEOGRAFIA FÍSICA NA FRONTEIRA DO CONHECIMENTO \\ Instituto de Geociências - Unicamp \\ Campinas - SP \\ 28 de Junho à 02 de Julho de 2017}

como quantificar a perda de partículas arrastadas no topo do solo, além de analisar os totais pluviométricos durante os períodos do processo de formação do escoamento.

\section{Materiais e métodos}

A presente pesquisa se desenvolveu na bacia hidrográfica do rio Maranduba, no Litoral Norte do estado de São Paulo, no município de Ubatuba. A área de estudo está inserida em bioma de Mata Atlântica e Guerra e Jorge (2009) salientam a pressão que o meio físico natural do município vem sofrendo frente à urbanização da área.

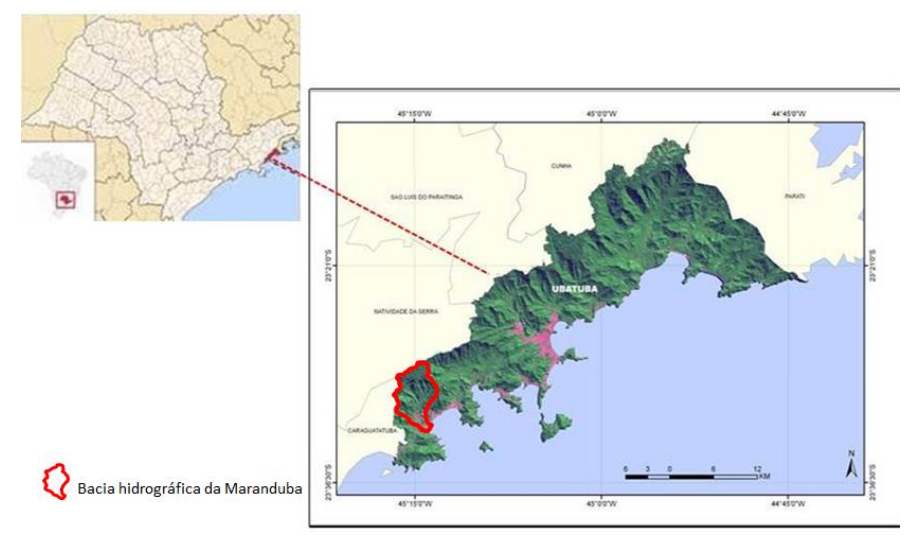

Figura 1- Localização da área de estudo. Fonte: Elaborado por Jorge, M. C. O. (2014)

Em relação às características geomorfológicas, o relevo apresenta altitudes de até 2.000 metros, com a presença de rupturas das vertentes e declives mais suaves, que dão origem a corredeiras e cachoeiras, assim como depósitos de tálus nas encostas (BUZATO, 2012).

Quanto ao clima, este pode ser classificado como tropical litorâneo úmido ou tropical atlântico, contando com temperatura média anual de $21^{\circ} \mathrm{C}$ (FERNANDES, 2009). O município de Ubatuba conta com os maiores totais pluviométricos do Brasil, possuindo média anual superior a $4000 \mathrm{~mm}$, chegando a 6000mm em anos extremos (TAVARES et al., 2002). A Serra do Mar, posicionada próxima à costa, é responsável pelo efeito orográfico, que associado aos fluxos atmosféricos originários do oceano e a uma zona de encontro de sistemas atmosféricos, propicia uma dinâmica de altos índices pluviais (PELLEGATTI \& GALVANI, 2010). Por fim, o solo, onde foi realizada a pesquisa, foi classificado como Latossolo Vermelho-Amarelo.

Foi construída uma estação experimental na área de estudo, em encosta que sofreu com ações antrópicas em área de material de empréstimo de sedimento (corte de encosta), apresentando solo degradado, logo, com pouca vegetação. Suas coordenadas são $-45^{\circ} 15^{\prime} 9,23^{\prime \prime}$ de Longitude e $23^{\circ} 32^{\prime} 46,87^{\prime \prime}$ de Latitude, localizada a 25,75 metros de altitude (PEREIRA, 2015). Foram instaladas 
XVII Simpósio Brasileiro

de Geografia Fisica Aplicada

I Congresso Nacional

de Geografia Física

\section{OS DESAFIOS DA GEOGRAFIA FÍSICA NA FRONTEIRA DO CONHECIMENTO \\ Instituto de Geociências - Unicamp \\ Campinas - SP \\ 28 de Junho à 02 de Julho de 2017}

três parcelas de erosão sem cobertura vegetal na encosta que foi recortada, no piso horizontal que se formou em uma declividade de $4^{\circ}$, sendo as calhas do modelo Gerlach (GUERRA, 2002).

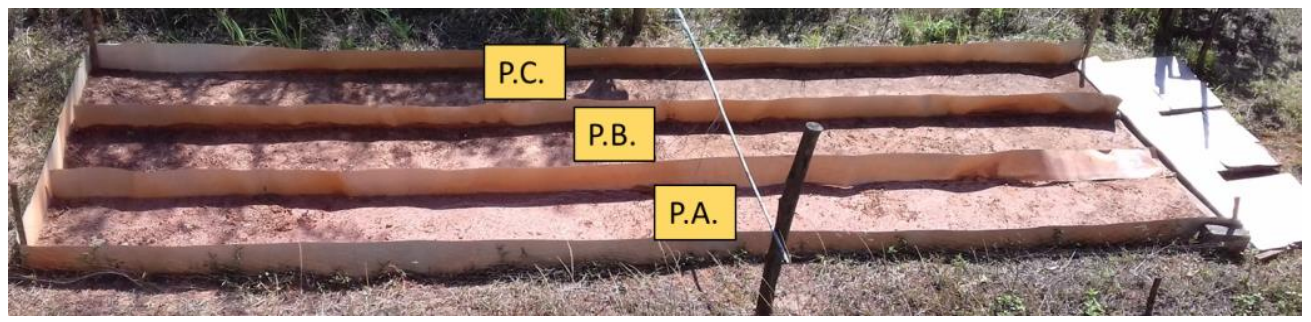

Figura 2- Parcelas de erosão para análise de escoamento superficial: Foto: Pereira, L. S. (2016)

As parcelas de erosão têm 10 x 1 m e estão conectadas a caixas que armazenam o escoamento com capacidade de 100 Litros. As parcelas de erosão são aferidas diariamente e do escoamento armazenado retira-se alíquota de 1 litro para analisar em laboratório os totais de perda de solo. Para relacionar com a perda de solo e água, foi feito o levantamento de dados de precipitação a partir de um pluviômetro de leitura diária instalado a 1 km de distância da estação (PEREIRA, 2015).

Os totais de perda de solo e água foram analisados temporalmente a partir do fluxo de escoamento superficial e relacionados ao total mensal de chuva entre o período de janeiro e dezembro de 2016. Para análises físicas e químicas, foram coletadas amostras de solo deformadas e volumétricas de 0-10 cm do solo nas parcelas de erosão A (PA), B (PB) e C (PC), caracterizando-se por ser um ambiente de solo exposto, sem cobertura vegetal, representando um sistema degradado (PEREIRA, 2015).

\section{Resultados e discussão}

Ao se promover uma relação entre os totais pluviométricos e as taxas de escoamento/perda de solo, os valores mais significativos encontram-se justamente nos meses de outubro e janeiro. É no mês de janeiro onde se observa altos índices, tanto de escoamento quanto perda de solo, o que pode ser explicado pela concentração de chuvas nesse mês, com a maior média dos totais pluviométricos do ano. Já no mês de outubro, observa-se o maior total de perda de solo do ano, porém o total de escoamento não é tão significativo se comparado aos demais, o que pode ser explicado através da ação das chuvas de baixa intensidade na região. As chuvas de baixa intensidade tornam-se um fator acelerador da erosão, pois propiciam uma umidade antecedente ao solo, que sendo encharcado constantemente, atinge seu ponto de saturação muito mais rápido, dando origem ao escoamento (PEREIRA, 2015). 


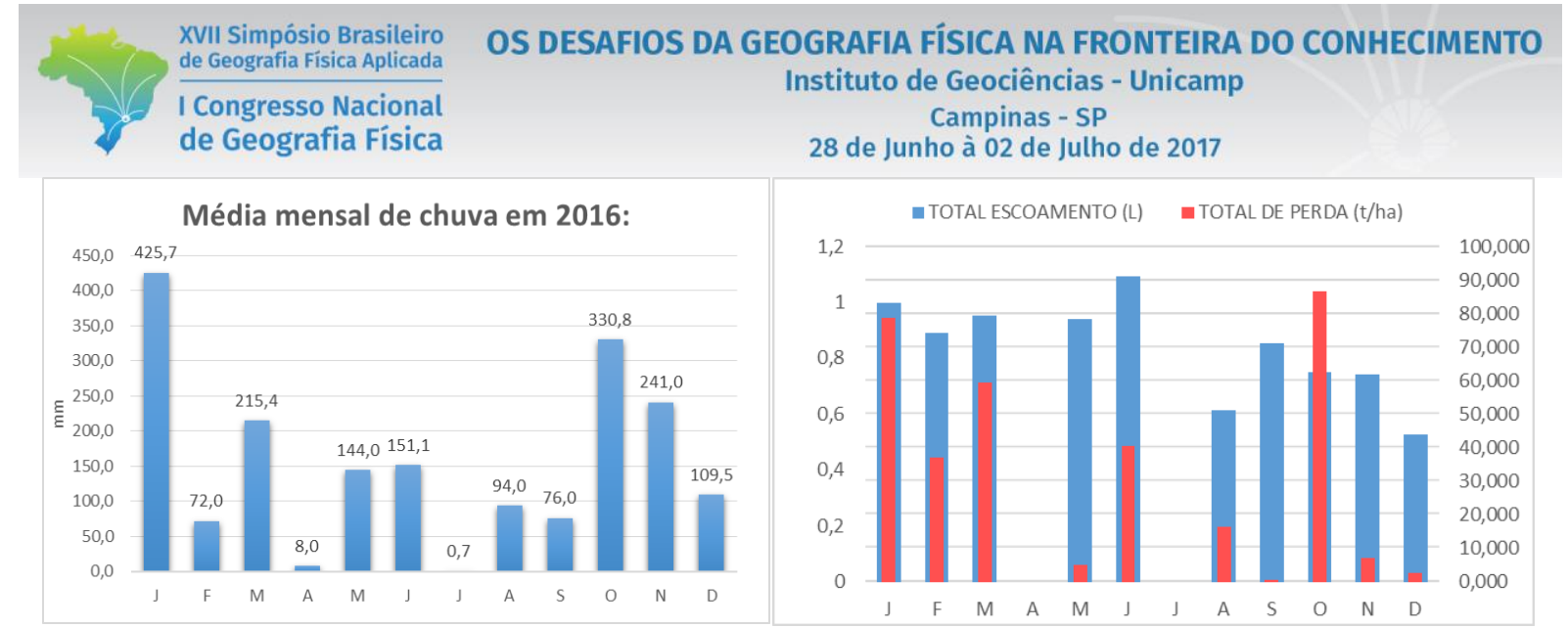

Figura 3 - Média mensal de chuva no ano de

Figura 4 - Média mensal de escoamento 2016. superficial e perda de solo no ano de 2016.

Os outros dois meses seguintes com maior significância de relação entre escoamento/perda de solo, são fevereiro e março. Em relação a fevereiro, os totais de perda de solo/escoamento podem ser explicados através de eventos chuvosos concentrados, já que a média dos índices pluviométricos durante o mês foi baixa; já em março, os números altos de perda de solo/escoamento podem ser explicados pela média mensal de chuvas ser mais alta, o que é natural do mês que encerra o verão. Nos meses de maio, agosto, junho, setembro e dezembro, aponta-se um grande índice de escoamento, porém, a figura 1 demonstra que as médias de chuva foram baixas nos mesmos, o que pode indicar chuvas isoladas e/ou espaçadas ao longo do mês, o que também pode ser aplicado ao mês de novembro, apesar de sua média mensal de chuva ser a terceira maior do ano.

Levando em consideração os totais de porosidade no solo, como mostra a Tabela I, as parcelas de erosão representam taxas de 33,8\% (PA), 33,45\% (PB) e 35,9\% (PC) na superfície de 0-10 cm. Nessa perspectiva, os resultados de densidade aparente da estação apresentaram elevado índice, com média de $1,7 \mathrm{~g} / \mathrm{cm}^{3}$, caracterizando um ambiente compactado, demonstrando que a rede porosa do solo é comprometida, como as áreas degradadas da presente pesquisa, onde ocorre a formação da erosão laminar. Rodrigues (2016), comparando áreas degradadas e áreas de floresta, constatou que os solos de áreas de floresta da mesma área de estudo apresentam uma rede porosa mais estruturada, onde o solo apresentou média de $1,2 \mathrm{~g} / \mathrm{cm}^{3}$ de densidade aparente. Tal fato pode ser explicado através da presença de vegetação, pois as raízes contribuem para a formação de poros no solo, assim como tende a garantir uma maior taxa de matéria orgânica, o que contribui para a formação de agregados (LIU et al., 2014). Em relação à matéria orgânica, as parcelas apresentaram média de $0,5 \%$, que é considerada uma baixa porcentagem, oferecendo maior susceptibilidade à erosão, pois a matéria orgânica favorece a ciclagem de nutrientes no solo, e seu baixo teor se torna desfavorável para o crescimento de vegetação (SILVA et al., 2014). Como ressaltam Fullen e Catt (2004) e Morgan (2005), valores inferiores a 3,5\% de matéria orgânica contribuem para maior susceptibilidade erosiva e instabilidade. 
XVII Simpósio Brasileiro de Geografia Fisica Aplicada

I Congresso Nacional de Geografia Física

\section{OS DESAFIOS DA GEOGRAFIA FÍSICA NA FRONTEIRA DO CONHECIMENTO \\ Instituto de Geociências - Unicamp \\ Campinas - SP \\ 28 de Junho à 02 de Julho de 2017}

Tabela I: Análises físico-químicas de amostras deformadas e volumétricas

\begin{tabular}{|c|c|c|c|c|c|c|c|c|c|c|}
\hline & & & & & \multicolumn{3}{|c|}{ Análises físicas } & & \multicolumn{2}{|c|}{ Análises químicas } \\
\hline & & & \multicolumn{2}{|c|}{ Arranjo poral } & \multicolumn{4}{|c|}{ Granulométrica \% } & \multirow[b]{2}{*}{ M.O. \% } & \multirow[b]{2}{*}{ pH } \\
\hline \multicolumn{2}{|l|}{ Pontos de coleta } & Profundidade & $\begin{array}{l}\text { Porosidad } \\
\text { e total \% }\end{array}$ & $\begin{array}{c}\text { Densidade } \\
\text { aparente } \\
\mathrm{g} / \mathrm{cm}^{3}\end{array}$ & Areia & Silte & Argila & $\begin{array}{c}\text { Classificação } \\
\text { textural (USDA, } \\
\text { 2014) }\end{array}$ & & \\
\hline Parcelas de erosão & $\mathrm{PA}$ & $0-10 \mathrm{~cm}$ & 33,8 & 1,7 & 47,3 & 17,9 & 34,8 & Franco argilo arenoso & 0,47 & 5,1 \\
\hline Parcelas de erosão & $\mathrm{PB}$ & $0-10 \mathrm{~cm}$ & 33,4 & 1,7 & 57,3 & 22,9 & 19,8 & Franco arenoso & 0,51 & 5,1 \\
\hline Parcelas de erosão & $\mathrm{PC}$ & $0-10 \mathrm{~cm}$ & 35,9 & 1,6 & 48,3 & 22 & 29,7 & Franco argilo arenoso & 0,51 & 5 \\
\hline
\end{tabular}

Tratando-se do pH, foi encontrada média de 5,1, o que indica solos ácidos, segundo Malavolta (1979), os solos ideais para o crescimento da vegetação possuem o pH entre 6 e 6,5. Jorge (2014) e Rodrigues (2016) apontam resultados semelhantes em suas pesquisas (média de 5,1 e 4,3, respectivamente), constatando também a presença de solos ácidos na área de estudo. Nas regiões tropicais é comum a presença de solos ácidos devido à energia do intemperismo.

Por fim, em relação à textura, as amostras demonstraram a maior presença da fração areia (PA 47,3\%; PB - 57,3\%; PC - 48,3\%) em detrimento de silte e argila, onde a classificação textural variou entre Franco arenoso e Franco argilo arenoso. Sendo assim, as frações com maior suscetibilidade à erosão são as frações silte e areia, principalmente areia fina, pois as mesmas não possuem capacidade de agregação, sendo o inverso do comportamento da argila, que é a fração que possui mais difícil remoção devido a sua maior capacidade de agregação (MORGAN, 2005).

\section{Conclusões}

Conclui-se, portanto, que as alterações antrópicas contribuem para o agravamento da degradação ambiental, em especial os processos erosivos, onde as chuvas intensas atreladas à falta de cobertura vegetal favorecem a degradação dos solos, a partir do aumento das taxas de perda de solo e água e alterações nas propriedades químicas e físicas do solo.

\section{Agradecimentos}

Agradecemos à Capes e ao PIBID pela bolsa, ao técnico de aferição da estação, Sebastião J. Oliveira, assim como agradecemos à Yoriko Kamiyama que cedeu espaço de seu sítio para a pesquisa.

\section{Bibliografia}

BUZATO, E. Avaliação de impactos ambientais no município de Ubatuba: uma proposta a partir dos geoindicadores. Tese (doutorado) - Universidade de São Paulo, 2012.

FANTIN, T.Y. Cobertura vegetal e erosão em entressulcos sob pastagem irrigada em Uberaba - MG. Tese (doutorado) - Universidade Estadual Paulista, Jaboticabal, 2012. 
FERNANDES, J. Percepção ambiental: as transformações no cotidiano de caiçaras de Ubatuba - SP na década de 1960 e na primeira década do século XXI. Dissertação (mestrado) - Universidade de Taubaté, Programa de Pós-Graduação em Ciências Ambientais, 2009.

FULLEN, M. A. e CATT, J. A. (2004). Soil Management - problems and solutions. Oxford: Oxford University Press. 2004

GUERRA, A.J.T e JORGE, M. Mapping hazard risk. Geography Review, v.22, n.3, p.11-13. 2009.

GUERRA, ANTONIO JOSÉ TEIXEIRA. Processos Erosivos nas Encostas. In: Geomorfologia - Exercícios, Técnicas e Aplicações. Orgs. S.B. Cunha e A.J.T. Guerra. Ed. Bertrand Brasil, 2.ed. p. 139-155. Rio de Janeiro/ RJ, 2002.

JORGE, M. C. O. Degradação dos solos no litoral norte paulista. In: Guerra, A. J. T. \& Jorge, M. C. O. (Orgs.). Degradação dos solos no Brasil. Ed. Bertrand Brasil. $1^{\circ}$ edição, 2014.

LIU, M-Y.; CHANG, Q-R.; QI, Y-B.; LIU, J.; CHEN, T. Aggregation and soil organic carbon fractions under different land uses on the tableland of the Loess Plateau of China. Catena 115 (2014) 19-28.

MALAVOLTA, E. - ABC da Adubação. Editora Agronômica CERES Ltda. São Paulo (SP), 1979.

MORGAN, R.P.C. Soil Erosion and Conservation. England: Blackwell, 2005.

PELLEGATTI, Cesar Henrique Gonçalves; GALVANI, Emerson. Avaliação da precipitação na Serra do MarSP em eventos de diferentes intensidade e duração. GEOUSP: Espaço e Tempo (Online), n. 27, p. 147-158, 2010

PEREIRA, L. S. Análises físico-químicas de solos com distintas coberturas vegetais e processos hidroerosivos em área degradada na bacia do rio Maranduba - Ubatuba, São Paulo. Dissertação (Mestrado em Geografia) Universidade Federal do Rio de Janeiro, Instituto de Geociências, Rio de Janeiro, 2015.

RODRIGUES, A.M. Diagnóstico da Degradação do Solo de Taludes de Corte na Bacia Hidrográfica do Rio Maranduba - Ubatuba/SP. Dissertação (mestrado) - Universidade Federal do Rio de Janeiro, Instituto de Geociências, Programa de Pós-Graduação em Geografia, 2016.

SILVA, A.S.; SILVA, I.F.; BANDEIRA, L.B.; DIAS, B.O.; NETO, L.F.S. Argila e matéria orgânica e seus efeitos na agregação em diferentes usos do solo. Ciência Rural, v.44, n.10, out, 2014.

TAVARES, R.; SANT'ANNA NETO, J. L. e SANTORO, J. Chuvas e escorregamentos no Litoral Norte Paulista entre 1988 e 2001. In: Anais do Encontro de Geógrafos Brasileiros. João Pessoa: AGB-DER. 2002. 